\title{
Pre-employment medical examinations - what is the issue?
}

\section{Klaus Seidenstücker ${ }^{1}$, Stefan Neidhardt ${ }^{1,2}$, Bernd Schepers ${ }^{1}$}

${ }^{1}$ German Maritime Health Association, Hamburg, Germany

${ }^{2}$ German Naval Institute of Maritime Medicine, Kronshagen, Germany

In a recent editorial contribution to this journal Tim Carter states that 'pre-employment medical examinations (PEMEs) are exercises in prediction' [1].

While anybody knows that predictions are tricky especially when they deal with the future you also might wonder how much of an 'exercise' PEMEs really are. How serious an exercise is it? How adequate and accurate and therefore, how valid and valuable can it be?

To find an answer we first would have to establish what a PEME should achieve. Carter in his editorial points to predicting the probability of disease in order to avoid situations that cannot be handled at sea and might pose a risk to the individual as well as eventually to crew and ship.

Is that all? It covers a precautionary aspect of PEMEs and mainly centres around the individual's health condition, preexisting states or dispositions. What we need in order to find them predominantly is a medical issue. Apply the right examination and test procedure and arrive at a judgement. But what exactly are we looking for and what therefore, is the adequate examination or test? Do we have a (worldwide) valid epidemiological database telling us what to look for? Do we have evidence on the predictive value of examination or test procedures regarding an employment on board? Do we have proof of the cut off criteria we apply?

As Carter states, the criteria to arrive at a judgement might depend on stakeholders view. We may like it or not: there is a range of different outcomes if we look at results of our medical examination from the point of view of the seafarer patient, the ship operator, employer, insurance - and even the examiners who do not wish to be held responsible for anything that goes wrong.

Regarding the risks of deteriorating health conditions, it is ours to determine what kind of examination and tests we want to apply. Of course, they should be evidence based and not abundant, profuse and helpless. It might be legitimate when addressing the predictive part of PEMEs to give our seafarer client some priority consideration as in the first place we are dealing with his health.

But what about the criteria for our judgement? The medical part is to assess the probability of a health risk. Whether that is acceptable or not is a responsibility we share with others: employer, ship operator, insurance etc. It definitely requires compromise.

There is however, another and maybe even more important or primary aspect in PEMEs. It is that of fitness for sea duty! This probably requires a different approach. We are no longer trying to predict the probability of disease. Instead we have to examine and test our clients for their physical and psychomental ability to perform their - routine and emergency - tasks of their specific job on board. In this respect we physicians are heavily dependent on a precise definition of such tasks by those who create, manage and hold responsibility for the job structures, the working and living environment on board. We are now much more answerable to nonmedical stakeholders regarding our methods and judgement. To answer the question how to examine, what to test and which criteria to employ there needs to be a demand profile provided by ship operators. As job profiles change with time and technology, a constant dialogue is inevitable to establish the necessary abilities and adapt the international guidelines for fitness examinations accordingly.

As the clinical inventory of testing might not always be adequate to answer fitness or aptitude questions, we should even consider to examine (or better evaluate) our clients in their training programmes or working environment. Colocation and cooperation with seafarer's educational institutes would not be the worst idea. 
The present structures and procedures definitely could be advanced to become a lot more reliable.

\section{CONFLICT OF INTEREST}

Klaus Seidenstücker: None declared; Stefan Neidhardt: Head of German Naval Institute of Maritime Medicine, a centre for shipboard and diving fitness and aptitude testing of military personnel. Bernd Schepers:
Former head of medical service, seafarer's occupational insurance - civil authority for PEME for German flagged ship's.

\section{REFERENCES}

1. Carter T. The evidence base for seafarer pre-employment medical examinations (PEMEs). Int Marit Health. 2017; 68(2): 75-76, doi: 10.5603/IMH.2017.0014, indexed in Pubmed: 28660608. 